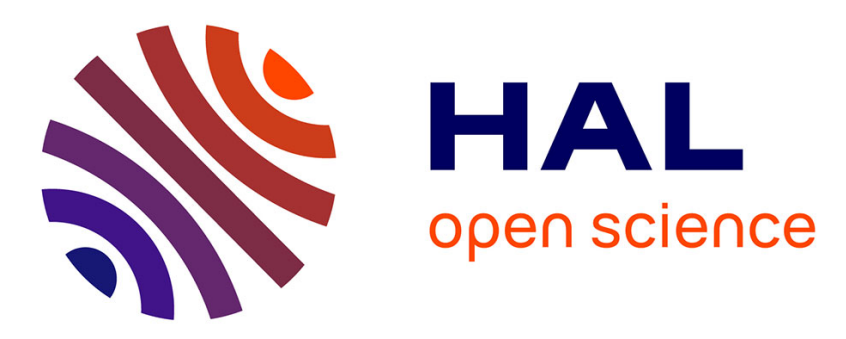

\title{
Atomic Insights into Nanoparticle Formation of Hydroxyfluorinated Anatase Featuring Titanium Vacancies
}

Wei Li, Monique Body, Christophe Legein, Olaf J. Borkiewicz, Damien

Dambournet

\section{To cite this version:}

Wei Li, Monique Body, Christophe Legein, Olaf J. Borkiewicz, Damien Dambournet. Atomic Insights into Nanoparticle Formation of Hydroxyfluorinated Anatase Featuring Titanium Vacancies. Inorganic Chemistry, 2016, 55 (14), pp.7182-7187. 10.1021/acs.inorgchem.6b01259 . hal-01489042

\section{HAL Id: hal-01489042 https://hal.sorbonne-universite.fr/hal-01489042}

Submitted on 14 Mar 2017

HAL is a multi-disciplinary open access archive for the deposit and dissemination of scientific research documents, whether they are published or not. The documents may come from teaching and research institutions in France or abroad, or from public or private research centers.
L'archive ouverte pluridisciplinaire HAL, est destinée au dépôt et à la diffusion de documents scientifiques de niveau recherche, publiés ou non, émanant des établissements d'enseignement et de recherche français ou étrangers, des laboratoires publics ou privés. 


\section{Atomic Insights into Nanoparticles Formation of Hydroxy- Fluorinated Anatase featuring Titanium Vacancies}

Wei Li,${ }^{\dagger}$ Monique Body, ${ }^{\S}$ Christophe Legein,${ }^{\S}$ Olaf J. Borkiewicz, ${ }^{\perp}$ and Damien Dambournet*,$\dagger$

$†$ Sorbonne Universités, UPMC Univ Paris 06, CNRS, UMR 8234, PHENIX, F-75005 Paris, France

$\S$ Université Bretagne Loire, Université du Maine, UMR CNRS 6283, Institut des Molécules et des Matériaux du Mans (IMMM), Avenue Olivier Messiaen, 72085 Le Mans Cedex 9, France

$\perp$ X-ray Science Division, Advanced Photon Source, Argonne National Laboratory, Argonne, Illinois, USA 
ABSTRACT: $\mathrm{TiO}_{2}$ anatase with exposed highly reactive (001) surface is commonly prepared using solution-based synthesis in the presence of a fluorinating agent acting as a structure directing agent. Recently, the solvothermal reaction of titanium tetraisopropoxide, in the presence of aqueous HF, has yielded to the stabilization of an oxy-hydroxyfluorinated anatase phase featuring cationic vacancies. In the present work, we have studied its formation mechanism revealing a solid-state transformation of a highly defective anatase phase having a hydroxyfluoride composition which subsequently evolves through oxolation reaction into an oxyhydroxyfluoride phase. Importantly, this work confirms that titanium alkoxide precursors can react with HF via a fluorolysis process yielding fluorinated molecular precursors which further condense producing new composition and structural features deviating from a well ordered anatase network.

\section{INTRODUCTION}

Titanium dioxide is a material of broad interests particularly in the field of conversion and energy storage. ${ }^{1}$ One of the most efficient approach to tune its physico-chemical properties relies on the stabilization of (001) type surfaces due to the occurrence of a large content of under-coordinated $\mathrm{Ti}$ atoms featuring enhanced interfacial reactivity. ${ }^{2}$ The common route to stabilize a large percentage of (001) surfaces uses solutionbased approach in the presence of a fluorinating agent which acts as a structure directing agent. ${ }^{3-5}$ The adsorption of fluorine atoms at the (001) surface directs anisotropic growth of anatase yielding crystals with a large content of highly reactive $\{001\}$ facets. $^{2}$ However, the chemical reactivity of fluorine, particularly $\mathrm{HF}$, toward titanium precursor, remains unclear. Consequently, the presence of fluoride into the anatase lattice is questionable. A comparison between the nucleophilic character of $\mathrm{HF}$ and $\mathrm{H}_{2} \mathrm{O}$ yields similar reactivity with a partial charge $\delta(\mathrm{F})=-0.42$ in $\mathrm{HF}$ and $\delta(\mathrm{O})=-0.40$ in $\mathrm{H}_{2} \mathrm{O} .{ }^{6}$ Thus, the presence of fluorine very likely induces modifications of the metal precursor at the molecular level and thus its chemical reactivity, ${ }^{7,8}$ eventually yielding new composition and structural features deviating from a well ordered anatase network. Titanium alkoxide precursors, such as titanium tetraisopropoxide, in the presence of aqueous HF, can react through hydrolysis and fluorolysis ${ }^{9}$ reactions. By analogy with the hydrolysis, the fluorolysis consists of the fluorination of a metal alkoxide bond according to:

$$
\mathrm{M}(\mathrm{OR})_{\mathrm{n}}+\mathrm{xHF} \rightarrow \mathrm{M}(\mathrm{OR})_{\mathrm{n}-\mathrm{x}} \mathrm{F}_{\mathrm{x}}+\mathrm{xROH}
$$

Because this process involves the protonation of the oxygen atom of the alkoxide group, it is favored in acidic condition. ${ }^{9}$ Subsequently, the formation of metal-fluorine bridges can result in the incorporation of fluorine within the lattice. ${ }^{10,11}$

Recently, we have shown that the mild solvothermal reaction of titanium alkoxide with aqueous $\mathrm{HF}$ yields an oxy-hydroxyfluoride compound $\mathrm{Ti}_{1-\mathrm{x}-\mathrm{y}} \square_{\mathrm{x}+\mathrm{y}} \mathrm{O}_{2-4(\mathrm{x}+\mathrm{y})} \mathrm{F}_{4 \mathrm{x}}(\mathrm{OH})_{4 \mathrm{y}}$ featuring the anatase type structure with cationic vacancies $(\square) .{ }^{12}$ From the obtained general chemical composition, it is shown that both hydrolysis and fluorolysis processes occurred during the synthesis, leading to the stabilization of as much as three types of anions in the vicinity of $\mathrm{Ti}^{4+}$. In the present article, we intend to understand the formation mechanism of $\mathrm{Ti}_{1-\mathrm{x}-\mathrm{y}} \square_{\mathrm{x}+\mathrm{y}} \mathrm{O}_{2-4(\mathrm{x}+\mathrm{y})} \mathrm{F}_{4 \mathrm{x}}(\mathrm{OH})_{4 \mathrm{y}}$ and to provide more insights into the chemical reactivity of titanium alkoxide toward HF. We employ a time dependent study to monitor structural and compositional changes of the as prepared nanoparticles through an ex-situ analysis combining X-ray diffraction (XRD), high-resolution Transmission Electron Microscopy (TEM), pair distribution function (PDF) and ${ }^{19} \mathrm{~F}$ solid-state NMR analyses.

\section{MATERIALS AND METHODS}

Synthesis: Titanium tetra-isopropoxide (TTIP, $\geq 97 \%$, Sigma Aldrich), isopropanol (Reag. Ph. Eur. grade, VMR), aqueous hydrofluoric acid solution (HF, $40 \mathrm{wt} \%$, Prolabo) and ethanol (EtOH, 96\% vol, VWR) were used as received. Syntheses via solvothermal process were carried out in a stainless steel autoclave with a $50 \mathrm{~mL}$ Teflon liner cup inside. In a typical experiment, $1.2 \mathrm{~mL}$ aqueous hydrofluoric acid solution was mixed with $24.8 \mathrm{~mL}$ isopropanol. The mixture was then poured into a Teflon liner cup containing $4 \mathrm{~mL}$ TTIP under stirring. After sealing the autoclave, the mixed solution was heated inside an oven at $90{ }^{\circ} \mathrm{C}$ for a certain time ranging from $1 \mathrm{~h}$ to $12 \mathrm{~h}$, and left to cool down to room temperature. The resulting white precipitate was washed twice with ethanol, centrifuged at 4400 rpm for $15 \mathrm{~min}$ and, dried at $80{ }^{\circ} \mathrm{C}$ under air for $2 \mathrm{~h}$. Further solvents removal was carried out using a tubular furnace under primary vacuum at $50{ }^{\circ} \mathrm{C}$ overnight.

Characterization methods: X-ray powder diffraction analysis were carried out using a Rigaku Ultima IV X-ray diffractometer equipped with a $\mathrm{Cu} \mathrm{K} \alpha$ radiation source $(\lambda=1.54059 \AA)$.

Transmission Electron Microscopy analysis were performed using a JEOL 2010 UHR microscope operating at $200 \mathrm{kV}$ equipped with a TCD camera.

Total scattering data were collected at the 11-ID-B beamline at the Advanced Photon Source at Argonne National Laboratory, using high energy X-rays $(\lambda=0.2128 \AA)$ allowing high values of momentum transfer $Q \max =22 \AA-1 .^{13,14}$ Onedimensional diffraction data were obtained by integrating the raw 2D total scattering data in Fit2D. ${ }^{15}$ PDFs, G(r), were extracted from the background and Compton scattering corrected data following Fourier transform within PDFgetX2. ${ }^{16}$ The PDFs were subsequently modeled using PDFgui. ${ }^{17}$ PDF peak fitting was performed using Fityk. ${ }^{18}$

Titanium was quantified using inductively coupled plasma atomic emission spectroscopy (ICP-AES) performed by the Service Central d'Analyse (Vernaison-CNRS).

${ }^{19} \mathrm{~F}$ solid-state magic angle spinning (MAS) NMR experiments were performed on a Bruker Avance III spectrometer operating at $7.0 \mathrm{~T}\left({ }^{19} \mathrm{~F}\right.$ Larmor frequency of $\left.282.2 \mathrm{MHz}\right)$, using a $1.3 \mathrm{~mm}$ CP-MAS probe head. The ${ }^{19} \mathrm{~F}$ MAS spectra were recorded using a Hahn echo sequence with an interpulse delay equal to one rotor period. The $90^{\circ}$ pulse length was set to $1.55 \mu$ s and the recycle delay was set to $20 \mathrm{~s} .{ }^{19} \mathrm{~F}$ spectra are referenced to $\mathrm{CFCl}_{3}$ and they were fitted by using the DMFit software. ${ }^{19}{ }^{19} \mathrm{~F}$ solid state NMR was also used to quantify the fluorine content on the studied samples by using reference samples. ${ }^{12}{ }^{19} \mathrm{~F}$ solid-state MAS NMR (Hahn echo) spectra were also recorded for $\mathrm{YF}_{3}$ and $\mathrm{LaF}_{3}$ and the masses of each 
sample in the rotor were measured. The fits of the spectra allow to determine the integrated intensities (I) for each sample. Since, for each sample, the recycle delays were chosen to ensure that the amount of signal detected is maximum (420 s for $\mathrm{YF}_{3}$ and $120 \mathrm{~s}$ for $\mathrm{LaF}_{3}$ ), we assume that the integrated intensities are proportional to the number of scans (256 for the studied samples and 16 for $\mathrm{YF}_{3}$ and $\mathrm{LaF}_{3}$ ) and to the molar quantity of fluorine atoms (n) in the rotor. This assumption is verified since the calculated $\mathrm{I} / \mathrm{n}$ ratio for $\mathrm{YF}_{3}$ and $\mathrm{LaF}_{3}$ are equal. The intensities per scan of the NMR signals of the studied samples, $\mathrm{I}_{1}$, and of $\mathrm{YF}_{3}$ (or $\mathrm{LaF}_{3}$ ), $\mathrm{I}_{2}$, allow to calculate the fluorine wt. $\%$ in the studied samples using the following formula where $\mathrm{m}$ and $\mathrm{M}$ are the mass and the molar mass, respectively:

$$
\begin{gathered}
\frac{I_{1}}{I_{2}}=\frac{n_{F}}{\frac{3 m_{Y F_{3}}}{M_{Y F_{3}}}} \\
F w t . \%=\frac{m_{F}}{m}=\frac{n_{F} M_{F}}{m}=\frac{3 m_{Y F_{3}}}{M_{Y F_{3}}} \frac{\mathrm{I}_{1}}{\mathrm{I}_{2}} \frac{\mathrm{M}_{\mathrm{F}}}{\mathrm{m}}
\end{gathered}
$$

\section{RESULTS AND DISCUSSION}

The solvothermal process performed at $90{ }^{\circ} \mathrm{C}$ for 12-hours of a solution containing titanium isopropoxide, isopropanol and aqueous HF allows to precipitate nanoparticles of anatase having the following chemical composition $\mathrm{Ti}_{0.78} \square_{0.22} \mathrm{O}_{1.12} \mathrm{~F}_{0.4}(\mathrm{OH})_{0.48}{ }^{12}$ To gain further insights into its formation mechanism, we employed a time dependent study performed at the early stage of the process, i.e. from 1-10 hours. A transition from a gel-state to precipitates starts to occur after 3-hours of reaction. Figure 1a shows the X-ray powder diffraction patterns of the dried gels and precipitates obtained from 1 to 5-hours of reaction. At the early stage of the reaction $(1 \mathrm{~h})$, the XRD shows a poorly crystallized pattern with a weak peak located at ca. $23.7^{\circ}$ and a shoulder $(2 \theta)$ assigned to the (100) and (101) planes of $\mathrm{TiOF}_{2}$ and anatase, respectively. As the reaction proceeds for up to 5-hours, the peak characteristic of $\mathrm{TiOF}_{2}$ progressively decreases and vanishes yielding a single phase of anatase. The particle size changes occurring during the 1-5 hours treatments were monitored by TEM. Figure 1b shows the high resolution TEM images of the dried gel obtained after $1 \mathrm{~h}$ of reaction. It points out the presence of two types of nanoparticles: (i) $3-4 \mathrm{~nm}$ amorphous particles (circled in yellow in Fig 1b) and (ii) ca. 7 $\mathrm{nm}$ nanoparticles featuring crystal lattice spacing of $0.19 \mathrm{~nm}$ corresponding to anatase (200) plans. Prolonging the reaction time yields to an increase of the population of the anatase crystallized nanoparticles and concomitantly reduces the amorphous one (Figure S1 in Supporting Information) highlighting a dissolution-recrystallization process.

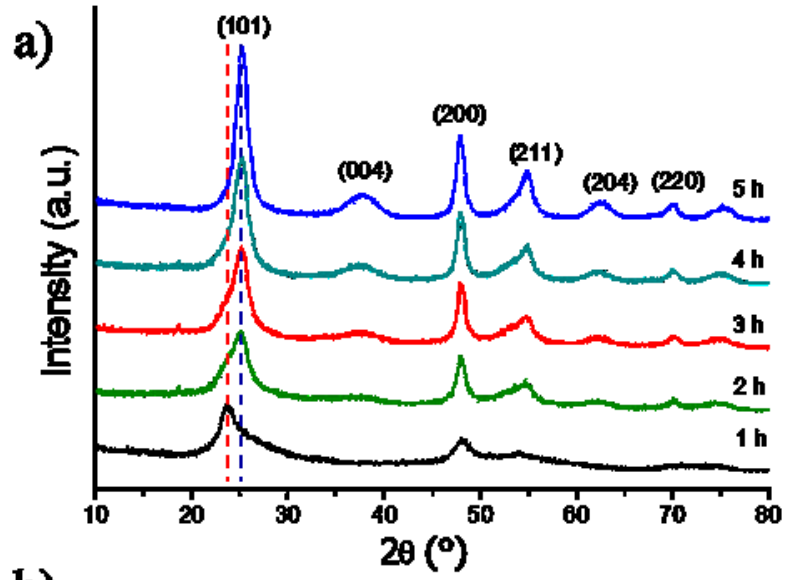

b)

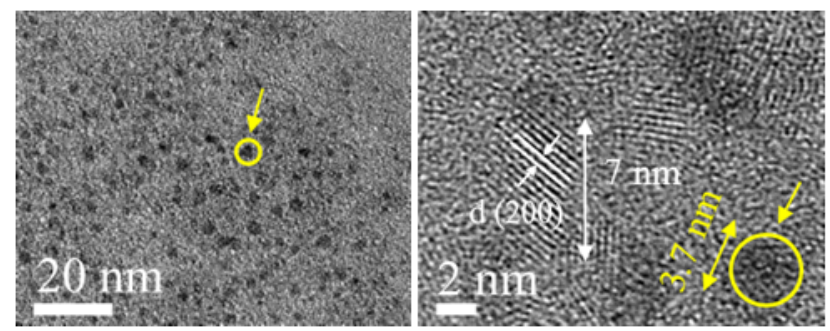

Figure 1. (a) XRD patterns of the samples synthesized within the first 5 hours. (hkl) planes of anatase are indicated. Red and blue dashed lines correspond to the (100) and (101) planes of $\mathrm{TiOF}_{2}$ and anatase, respectively. (b) HRTEM images of the sample obtained after $1 \mathrm{~h}$ of reaction.

PDF analysis, which permits to study both amorphous and nanostructured materials at the atomic scale, ${ }^{20}$ was carried out on samples obtained at different stages of the process. Interatomic distances $(r)$ can be visualized over a $r$-range comprising local structural features and the length scale of ordered structural domains. Figure 2 shows the evolution of the interatomic distances at the local range order, i.e. 1-4 $\AA$, for the samples prepared from 1 to 5 hours. The position of the first peak located at ca. $1.93 \AA$ corresponding to $\mathrm{Ti}-\mathrm{O} / \mathrm{F}$ bond length does not vary significantly while the reaction time increases (Figure S2). Moreover, the peak area which reflects the coordination number of $\mathrm{Ti}^{4+}$ remains constant along the reaction, i.e. 6 -fold coordinated. The most pronounced deviations in the local structure occur at peaks located at ca. $2.7 \AA$ and $3.1 \AA$ characterizing the first anion coordination sphere of anion (X-X with $\mathrm{X}=\mathrm{F}^{-}, \mathrm{OH}^{-}$and $\mathrm{O}^{2-}$ ) and the second nearestneighbor $\mathrm{Ti} \cdots \mathrm{Ti}$ distance, respectively. According to partial PDFs analysis of references samples (Figure S3), these peaks were assigned to anion-anion distance in $\mathrm{TiOF}_{2}$ and edgesharing $\mathrm{Ti}-\mathrm{Ti}$ in $\mathrm{TiO} 2$ anatase, respectively. Accordingly, local structural changes visualized by PDF point out the progressive dissolution of a TiOF2-like phase and the concomitant growth of anatase. This structural change is accompanied by an increase of the length scale of the PDF features (Figure S4) indicating a progressive ordering upon reaction. 


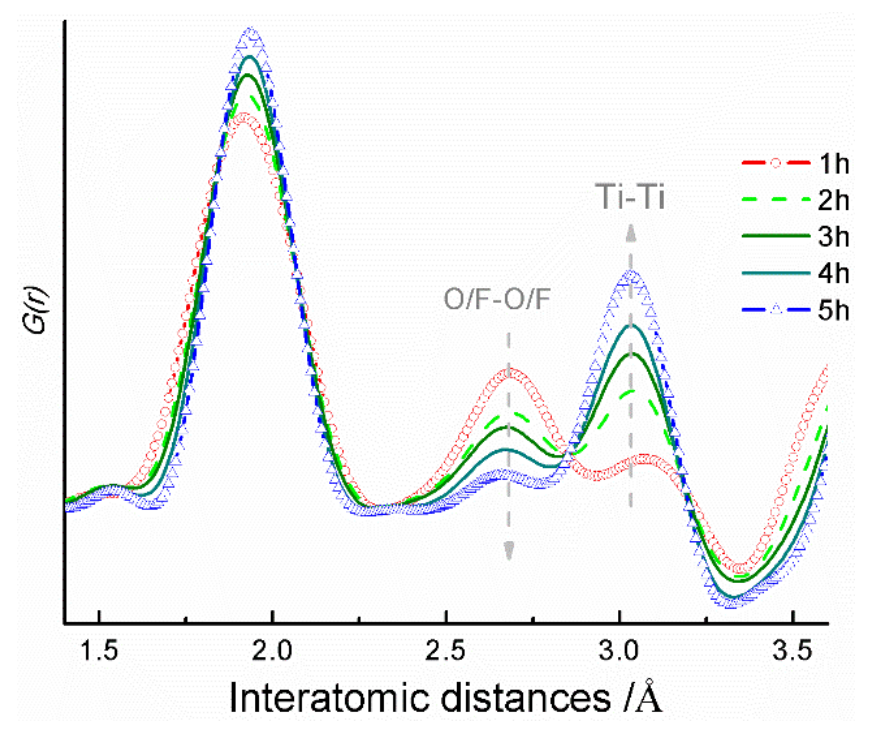

Figure 2. Evolution of the PDFs of the samples prepared from 1 to 5-hours. Arrows indicate peak intensity evolutions upon increasing reaction time.

To identify structural changes and evaluate the evolution of the coherent domain (particle size and/or length scale of the range order) during the solvothermal process, PDF data were refined against structural models using a real-space refinement (Figure 3). ${ }^{17}$ Structural changes occurring at the early stage of the reaction were followed by considering a two phases analysis including a $\mathrm{TiOF}_{2}$-like and anatase models. The refinements showed that the $\mathrm{TiOF}_{2}$-like phase features a range ordering limited to $8 \AA$. This phase can thus be related to the amorphous 3-4 nm particles observed by TEM. The difference between the local ordering and the particle size highlights the amorphous nature of this phase. A quantitative phase analysis (Figure S5) allowed following the progressive appearance (from ca. $40 \%$ to $100 \%$ ) of anatase at the expense of the amorphous $\mathrm{TiOF}_{2}$-like phase. The growth of anatase nanoparticles yields an increase of the PDF peaks intensity. Consequently, the accuracy of the PDF refinement characterized by the reliability factor $\mathrm{R}_{\mathrm{w}}$, largely improves which allows extracting reliable structural parameters. Note that for the sample obtained after 1-hour of reaction, the limited $r$-range prevents detailed structural analysis.

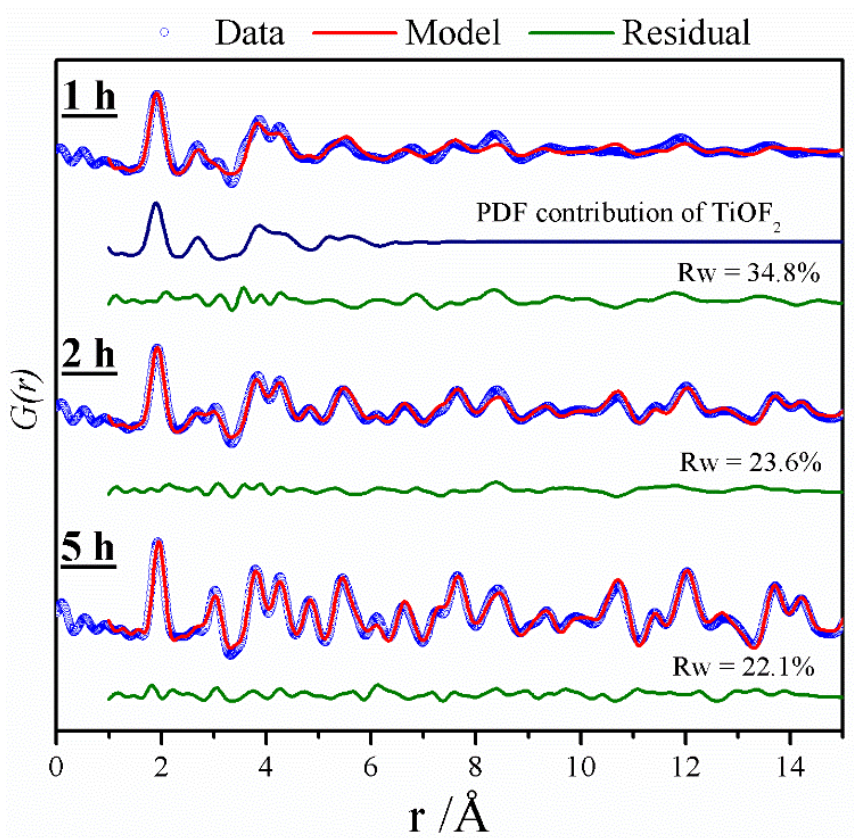

Figure 3. PDF refinements of the samples prepared at 1, 2 and 5 -hours reaction time. Blue and red curves refer to the experimental and modeled data, respectively. The green curve refers to the difference curve between the experimental and calculated data. For $\mathrm{t}=1 \mathrm{~h}$, the contribution of the $\mathrm{TiOF}_{2}$-like phase to the PDF data is shown.

The evolution of the anatase structural features extracted from PDF refinements was monitored upon reaction and up to the formation of $\mathrm{Ti}_{0.78} \square_{0.22} \mathrm{O}_{1.12} \mathrm{~F}_{0.4}(\mathrm{OH})_{0.48}(12 \mathrm{~h})$. More specifically, the titanium vacancies' concentration deduced by refining the Ti rate occupancy and the particle size (coherence length of ordered structural domains) were reported in Figure 4 as a function of the reaction time. Most notably, the particle size increases sparsely while the cationic vacancies' content decreases significantly. This structural re-arrangement is particularly pronounced from 2 to 6 hours.

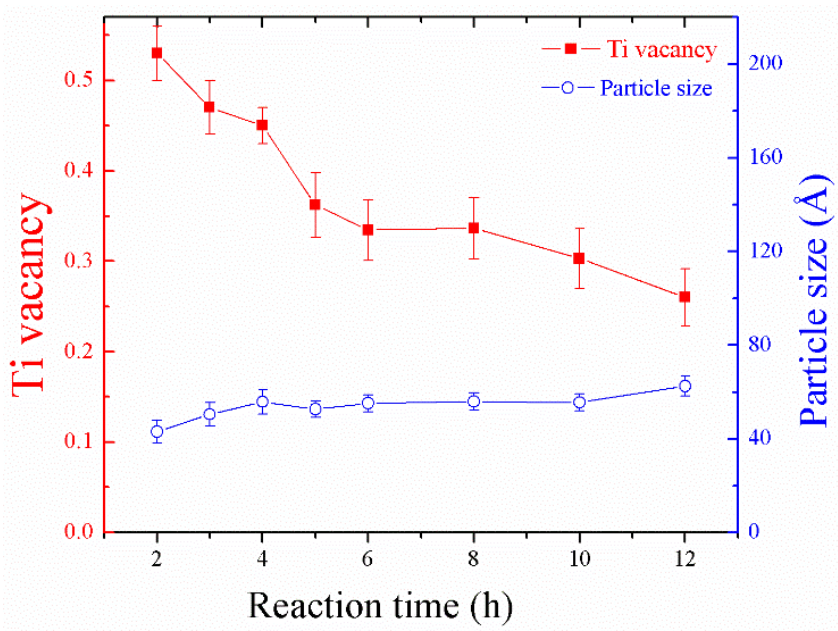

Figure 4. Evolution of the titanium vacancy concentration and particle size of the anatase phase upon reaction.

Since the particle sizes increase sparsely upon reaction, the origin of the decrease of the titanium vacancy concentration can be related to a solid-state transformation rather than other processes (particle growth or dissolution/recrystallization process). Similar process has been shown to occur during the formation of anatase $\mathrm{TiO}_{2}$ under hydrothermal conditions. ${ }^{21}$ To 
identify the reactions underpinning the solid-state transformation of anatase, we monitored the evolution of the chemical composition upon reaction. Chemical compositions were assessed by combining elemental analyses obtained by ${ }^{19} \mathrm{~F}$ NMR and ICP-AES as well as PDF data. For the samples obtained after 2-4 hours of reaction, elemental analyses gave a quantity corresponding to the element contribution in both $\mathrm{TiOF}_{2}$-like and anatase phases. Using the quantitative phase analysis obtained by PDF refinements (molar \% of $\mathrm{TiOF}_{2}$ and anatase), the F/Ti molar ratio in anatase was assessed according to:

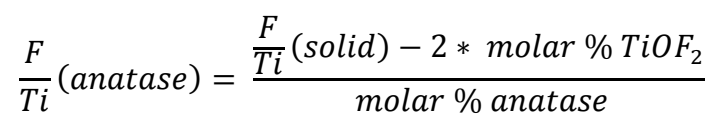

where $\mathrm{F} / \mathrm{Ti}$ (solid) is the $\mathrm{F} / \mathrm{Ti}$ molar ratio obtained by elemental analyses. Note that the $\mathrm{F} / \mathrm{Ti}$ molar ratio in $\mathrm{TiOF}_{2}$ was set to two. The hydroxyls content in anatase was deduced using the general formula $\mathrm{Ti}_{1-x-y} \square_{x+y} \mathrm{O}_{2-4(\mathrm{x}+\mathrm{y})} \mathrm{F}_{4 \mathrm{x}}(\mathrm{OH})_{4 \mathrm{y}}$. The results are gathered in Table 1.

Table 1: Estimated chemical composition of the anatase phase at different reaction times of the solvothermal process.

\begin{tabular}{cccc}
\hline $\begin{array}{c}\text { Time } \\
\text { (h) }\end{array}$ & $\begin{array}{c}\text { F/Ti } \\
\text { molar } \\
\text { ratio }\end{array}$ & $\begin{array}{c}\text { Calculated } \\
\text { F/Ti in } \\
\text { anatase }\end{array}$ & Composition of anatase \\
\hline 2 & 1.33 & 0.94 & $\mathrm{Ti}_{0.50} \square_{0.50} \mathrm{~F}_{0.47}(\mathrm{OH})_{1.53}$ \\
3 & 1.24 & 0.97 & $\mathrm{Ti}_{0.54} \square_{0.46} \mathrm{O}_{0.16} \mathrm{~F}_{0.53}(\mathrm{OH})_{1.31}$ \\
4 & 1.04 & 0.88 & $\mathrm{Ti}_{0.57} \square_{0.43} \mathrm{O}_{0.28} \mathrm{~F}_{0.50}(\mathrm{OH})_{1.22}$ \\
5 & 0.75 & 0.75 & $\mathrm{Ti}_{0.63} \square_{0.37} \mathrm{O}_{0.52} \mathrm{~F}_{0.51}(\mathrm{OH})_{0.97}$ \\
12 & 0.51 & 0.51 & $\mathrm{Ti}_{0.78} \square_{0.22} \mathrm{O}_{1.12} \mathrm{~F}_{0.4}(\mathrm{OH})_{0.48}$ \\
\hline
\end{tabular}

a obtained by ICP-AES (Ti) and NMR (F)

At the early stage of the reaction, a composition featuring $50 \%$ of cationic vacancies was obtained. Considering the general formula $\mathrm{Ti}_{1-x-y} \square_{x+y} \mathrm{O}_{2-4(\mathrm{x}+\mathrm{y})} \mathrm{F}_{4 \mathrm{x}}(\mathrm{OH})_{4 y}$, it implies the absence of oxide anions due to the sole presence of monovalent anions, i.e. $\mathrm{Ti}_{0.5} \square_{0.5} \mathrm{~F}_{0.47}(\mathrm{OH})_{1.53}$. The composition reveals the presence of $76.5 \%$ and $23.5 \%$ of $\mathrm{OH}$ groups and fluorine, respectively. From Table 1, it can be shown that upon reaction the hydroxyfluoride evolves into an oxy-hydroxyfluoride composition. The appearance of $\mathrm{O}^{2-}$ indicates a solid state transformation induced either by oxolation or defluorination reactions. The variation of the relative proportions for the three anions $\mathrm{F}^{-}, \mathrm{OH}^{-}$and $\mathrm{O}^{2-}$ (Figure 5) shows that the relative proportion of $\mathrm{F}^{-}$only slightly varies showing that the solidstate transformation of anatase is induced by oxolation reactions yielding to an oxide-rich hydroxyfluoride phase with lower titanium vacancies content. Note that a slight parallel hydrolytic cleavage of Ti-F-bonds contributing to a lowering of the titanium vacancies' concentration cannot be ruled out.

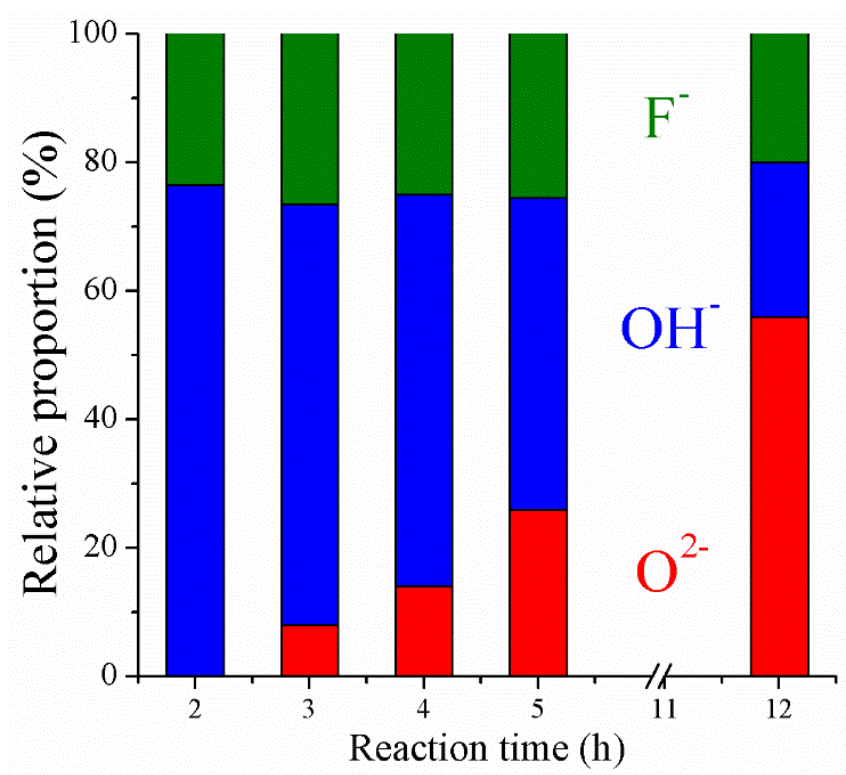

Figure 5. Evolution of the relative proportions of anions in the anatase phase.

Deeper insight into the reaction mechanism was studied by following the evolution of the fluorine local environment upon reaction using high resolution ${ }^{19} \mathrm{~F}$ solid-state MAS NMR. Spectra (Figure 6) of the samples prepared at 1, 2, 3, 4, 6, 8 and 10 hours reaction time show three distinct lines which were previously assigned to fluorine in the vicinity of different numbers of titanium atoms and/or titanium vacancies. The species $\mathrm{Ti}_{3}-\mathrm{F}, \mathrm{Ti}_{2} \square-\mathrm{F}$ and $\mathrm{Ti} \square_{2}-\mathrm{F}$ have been previously identified in anatase $\mathrm{Ti}_{0.78} \square_{0.22} \mathrm{O}_{1.12} \mathrm{~F}_{0.4}(\mathrm{OH})_{0.48}$ at $-88 \mathrm{ppm},-4 \mathrm{ppm}$ and 98 ppm, respectively. ${ }^{12}$ Within pure $\mathrm{TiOF}_{2}$, an anion is surrounded by two titanium atoms. Nevertheless, oxide anions can be substituted by $\mathrm{OH}$ groups yielding titanium vacancies ${ }^{22}$ so that it exists an additional coordination mode, $\mathrm{Ti} \square-\mathrm{X}(\mathrm{X}=$ $\mathrm{O}, \mathrm{F})$, for the anions. In hydroxylated $\mathrm{TiOF}_{2}$, i.e. $\mathrm{Ti}_{0.90} \square_{0.10} \mathrm{O}_{0.60}(\mathrm{OH})_{0.74} \mathrm{~F}_{1.66}$, the species $\mathrm{Ti}_{2}-\mathrm{F}$ have been identified at 12 and $20 \mathrm{ppm}$ and the species Ti $\square-\mathrm{F}$ at 146 and 182 ppm. ${ }^{23}$ Based on these previous studies, the NMR lines used for the fits of the ${ }^{19} \mathrm{~F}$ solid-state MAS NMR spectra have been assigned to $\mathrm{Ti}_{3}-\mathrm{F}, \mathrm{Ti}_{2} \square-\mathrm{F}, \mathrm{Ti}_{2}-\mathrm{F}, \mathrm{Ti} \square_{2}-\mathrm{F}$ and $\mathrm{Ti} \square-\mathrm{F}$ species (see Supporting Information, Figures S6-11 and Tables S17).

For a reaction time of 1 hour, the ${ }^{19} \mathrm{~F}$ isotropic chemical shifts $\left(\delta_{\text {iso }}\right)$ of the two main contributions are in-between those of $\mathrm{Ti}_{2} \square_{1}-\mathrm{F}$ and $\mathrm{Ti}_{2}-\mathrm{F}$ and those of $\mathrm{Ti} \square_{2}-\mathrm{F}$ and $\mathrm{Ti} \square-\mathrm{F}$, respectively, in agreement with the simultaneous occurrence of $\mathrm{TiOF}_{2}-$ like and anatase phases. The reconstruction of the spectrum pointed out a ${ }^{19} \mathrm{~F}$ isotropic chemical shift $\left(\delta_{\text {iso }}\right)$ located at 144.2 ppm which can be assigned to Ti $\square$-F species. The occurrence of such an environment indicates that the $\mathrm{TiOF}_{2}$-like phase features titanium vacancies due to the substitution of oxide by mono-valent anions, i.e. $\mathrm{Ti}_{1-\mathrm{x}} \square_{\mathrm{x}} \mathrm{O}_{1-4 \mathrm{x}}(\mathrm{OH}, \mathrm{F})_{2+4 \mathrm{x}}$.

For longer reaction time $(2,3$ and $4 \mathrm{~h})$, the ${ }^{19} \mathrm{~F} \delta_{\text {iso }}$ values of the NMR lines assigned to $\mathrm{F}$ atoms coordinated to one Ti atom are smaller. The occurrence of Ti $\square$-F species is then doubtful in these samples. The ${ }^{19} \mathrm{~F} \delta_{\text {iso }}$ values of the NMR lines assigned to $\mathrm{Ti}_{2} \square-\mathrm{F}$ and $\mathrm{Ti}_{2}-\mathrm{F}$ species decrease when the reaction time increases up to $6 \mathrm{~h}$ and then remain almost constant. Moreover, the relative intensity of the NMR line at $\sim-88 \mathrm{ppm}$ (or less for a reaction time of 1 hour) assigned to $\mathrm{Ti}_{3}-\mathrm{F}$ species increases with the reaction time up to $6 \mathrm{~h}$ and then remains 
constant. All these statements confirm the progressive dissolution of a $\mathrm{TiOF}_{2}$-like phase and the concomitant growth of anatase. Finally, the ${ }^{19} \mathrm{~F}$ solid-state MAS NMR spectra of the samples prepared at 6,8 and 10 hours reaction time are similar showing that the local environment of fluorine doesn't evolve anymore.

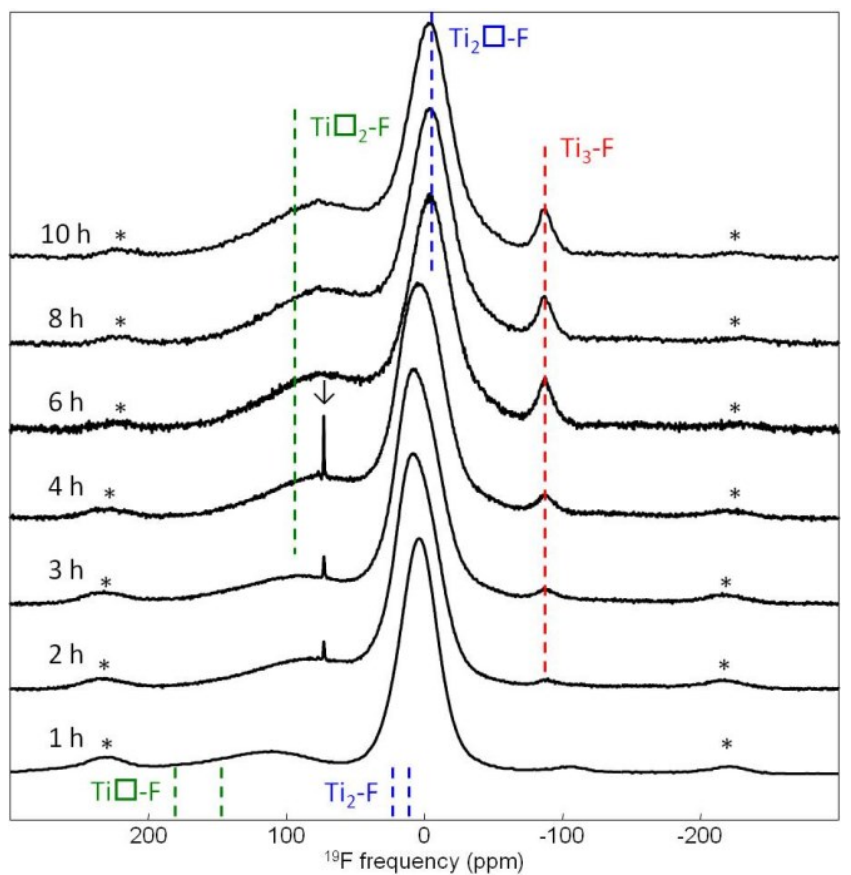

Figure 6. ${ }^{19} \mathrm{~F}$ solid-state MAS (64 kHz) NMR spectra of the samples prepared at $1,2,3,4,6,8$ and 10 hours reaction time. The dashed lines indicate the isotropic chemical shifts of $\mathrm{Ti}_{3}-\mathrm{F}$, $\mathrm{Ti}_{2} \square-\mathrm{F}$ and $\mathrm{Ti} \square_{2}-\mathrm{F}$ environments in $\mathrm{Ti}_{0.78} \square_{0.22} \mathrm{O}_{1.12} \mathrm{~F}_{0.4}(\mathrm{OH})_{0.48}{ }^{12}$ and of $\mathrm{Ti}_{2}-\mathrm{F}$ and $\mathrm{Ti} \square-\mathrm{F}$ environments in $\mathrm{Ti}_{0.90} \square_{0.10} \mathrm{O}_{0.60}(\mathrm{OH})_{0.74} \mathrm{~F}_{1.66 .}{ }^{23}$ Spinning sidebands of the main contribution are marked with an asterisk. The arrow indicates an unidentified impurity.

At the early stage of the reaction, the simultaneous presence of two phases having two different structural features is due to the extent of fluorolysis over hydrolysis reaction. The predominance of the $\mathrm{TiOF}_{2}$-like phase indicates that fluorolysis occurs faster than hydrolysis. Highly fluorinated molecular precursors likely assemble to form $\mathrm{Ti}_{1-\mathrm{x}} \square_{\mathrm{x}} \mathrm{O}_{1-4 \mathrm{x}}(\mathrm{OH}, \mathrm{F})_{2+4 \mathrm{x}}$ while lower fluorine containing species lead to the formation of the anatase network. The presence of a large content of titanium vacancies indicates the preponderance of $\mathrm{OH}$ groups over $\mathrm{O}^{2-}$ anions. The later are formed by oxolation reaction which decreases the content of titanium vacancies. The observed solid-state transformation occurring in anatase has been previously mentioned to occur during the hydrothermal synthesis of nanoparticles. ${ }^{21}$ The ageing process of an amorphous $\mathrm{TiO}_{2} \bullet 1.6 \mathrm{H}_{2} \mathrm{O}$ compound yielded anatase $\mathrm{TiO}_{2}$ which according to Sauvage et al occurred via a slow solid dehydration process. Very likely this process implies oxolation reactions. Interestingly, sol-gel processes excluding fluorine have shown to yield anatase with titanium vacancies which are due to the presence of $\mathrm{OH}$ groups substituting $\mathrm{O}^{2-}$, i.e. $\mathrm{Ti}_{0.81} \square_{0.19} \mathrm{O}_{1.24}(\mathrm{OH})_{0.76}{ }^{25}$ Overall, the formation of anatase implies the structural re-arrangement of an hydroxide (and hydroxyfluoride in the presence of fluorine) featuring a large content of titanium vacancies which can largely impact on physico-chemical properties. ${ }^{12}$

\section{CONCLUSION}

The solvothermal reaction of titanium tetraisopropoxide, in the presence of aqueous HF, has been investigated to shed lights upon the formation mechanism of highly fluorinated anatase phase featuring titanium vacancies. It is shown that HF reacts readily with titanium isopropoxide yielding both an amorphous phase related to $\mathrm{TiOF}_{2}$ and a fluorinated anatase. At the early stage of the reaction, the anatase anionic sublattice was shown to contain only monovalent fluoride and hydroxide anions. During reaction, $\mathrm{TiOF}_{2}$ completely dissolves while the anatase nanoparticles re-arrange through a solidstate transformation. This solid-phase transformation implies the condensation of $\mathrm{OH}$ groups by oxolation reaction yielding oxide anions and a concomitant decrease of the cationic vacancies. The combined uses of ${ }^{19} \mathrm{~F}$ solid-state NMR and PDF analyses were decisive in understanding the formation mechanism of fluorinated anatase. Finally, this work confirms that titanium alkoxide precursors can react with HF via a fluorolysis process yielding fluorinated molecular precursors which further condense producing new composition and structural features deviating from a well ordered anatase network.

\section{ASSOCIATED CONTENT}

Supporting Information. Additional information such as TEM images, PDF analysis, fits of ${ }^{19} \mathrm{~F}$ MAS NMR spectra.

\section{AUTHOR INFORMATION}

\section{Corresponding Author}

* Email: damien.dambournet@upmc.fr

Notes

The authors declare no competing financial interests.

\section{ACKNOWLEDGMENT}

The research leading to these results has received funding from the People Programme (Marie Curie Actions) of the European Union's Seventh Framework Programme (FP7/2007-2013) under REA grant agreement $n^{\circ}$ [321879] (FLUOSYNES). S. Casale is acknowledged for HRTEM measurement. The work done at the Advanced Photon Source, an Office of Science User Facility operated for the U.S. Department of Energy (DOE) Office of Science by Argonne National Laboratory, was supported by the U.S. DOE under Contract No. DE-AC02-06CH11357. 


\section{REFERENCES}

(1) Chen, X.; Mao, S. S. Chem. Rev. 2007, 107, 2891-2959.

(2) Yang, H. G.; Sun, C. H.; Qiao, S. Z.; Zou, J.; Liu, G.; Smith, S. C.; Cheng, H. M.; Lu, G. Q. Nature 2008, 453, 638-641. (3) Liu, G.; Yang, H. G.; Pan, J.; Yang, Y. Q.; Lu, G. Q. (Max); Cheng, H.-M. Chem. Rev. 2014, 114, 9559-9612. (4) Cargnello, M.; Gordon, T. R.; Murray, C. B. Chem. Rev. 2014, 114, 9319-9345.

(5) Menzel, R.; Duerrbeck, A.; Liberti, E.; Yau, H. C.; McComb, D.; Shaffer, M. S. P. Chem. Mater. 2013, 25, 2137-2145.

(6) Livage, J.; Henry, M.; Sanchez, C. Prog. Solid State Chem. 1988, 18, 259-341.

(7) Sanchez, C.; Livage, J.; Henry, M.; Babonneau, F. J. NonCryst. Solids 1988, 100, 65-76.

(8) Metal Oxide Chemistry and Synthesis: From Solution to Solid State - $\quad$ J.-P. Jolivet http://eu.wiley.com/WileyCDA/WileyTitle/productCd0471970565.html.

(9) Rüdiger, S.; Kemnitz, E. Dalton Trans. 2008, 1117-1127.

(10) Kemnitz, E.; Groß, U.; Rüdiger, S.; Shekar, C. S. Angew. Chemie Int. Edition 2003, 42, 4251-4254.

(11) Rüdiger, S. K.; Groß, U.; Feist, M.; Prescott, H. A.; Shekar, S. C.; Troyanov, S. I.; Kemnitz, E. J. Mater. Chem. 2005, 15, 588-597.

(12) Li, W.; Corradini, D.; Body, M.; Legein, C.; Salanne, M.; Ma, J.; Chapman, K. W.; Chupas, P. J.; Rollet, A.-L.; Julien, C.; Zhagib, K.; Duttine, M.; Demourgues, A.; Groult, H.; Dambournet, D. Chem. Mater. 2015, 27, 5014-5019.

(13) Chupas, P. J.; Qiu, X.; Hanson, J. C.; Lee, P. L.; Grey, C. P.; Billinge, S. J. L. J. Applied Cryst. 2003, 36, 1342-1347.
(14) Chupas, P. J.; Chapman, K. W.; Lee, P. L. J. Applied Cryst. 2007, 40, 463-470.

(15) Hammersley, A. P.; Svensson, S. O.; Hanfland, M.; Fitch, A. N.; Hausermann, D. High Pressure Research 1996, 14, 235-248.

(16) Qiu, X.; Thompson, J. W.; Billinge, S. J. L. J. Appl. Cryst. 2004, 37, 678-678.

(17) Farrow, C. L.; Juhas, P.; Liu, J. W.; Bryndin, D.; Božin, E. S.; Bloch, J.; Proffen, T.; Billinge, S. J. L. J. Phys.: Condens. Matter 2007, 19, 335219.

(18) Wojdyr, M. J. Applied Cryst. 2010, 43, 1126-1128.

(19) Massiot, D.; Fayon, F.; Capron, M.; King, I.; Le Calvé, S.; Alonso, B.; Durand, J.-O.; Bujoli, B.; Gan, Z.; Hoatson, G. Magn. Reson. Chem. 2002, 40, 70-76.

(20) Billinge, S. J. L.; Kanatzidis, M. G. Chem. Commun. 2004, 749-760.

(21) Mi, J.-L.; Jensen, K. M. Ø.; Tyrsted, C.; Bremholm, M.; Iversen, B. B. CrystEngComm 2015, 17, 6868-6877.

(22) Demourgues, A.; Penin, N.; Durand, E.; Weill, F.; Dambournet, D.; Viadere, N.; Tressaud, A. Chem. Mater. 2009, 21, $1275-1283$.

(23) Ma, J.; Body, M.; Legein, C.; Dambournet, D. to be submitted.

(24) Patra, S.; Davoisne, C.; Bruyère, S.; Bouyanfif, H.; Cassaignon, S.; Taberna, P.-L.; Sauvage, F. Part. Part. Syst. Charact. 2013, 30, 1093-1104.

(25) Grey, I. E.; Wilson, N. C. J. Solid State Chem. 2007, 180, 2 , 670-678. 
For Table of Contents Only.

Structural re-arrangement occurring in anatase nanoparticles synthetized in a solvofluorothermal conditions

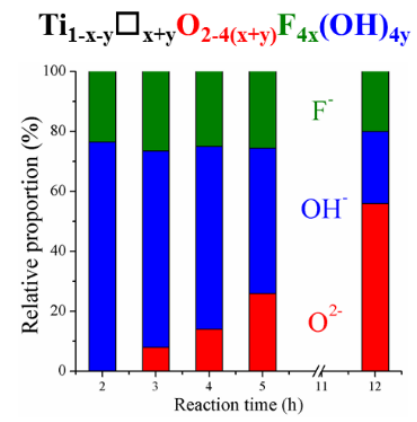

